\title{
Burst or conventional peripheral nerve field stimulation for treatment of neuropathic facial pain
}

\author{
Manning $\mathrm{A}^{1}$, Ortega Garcia $\mathrm{R}^{1}$, Moir $\mathrm{L}^{1}$, Edwards $\mathrm{T}^{1}$, Aziz TZ ${ }^{1,2,3}$, Bojanic $\mathrm{S}^{1}$, Green \\ $\mathrm{AL}^{1,2,3}$, FitzGerald JJ ${ }^{1,2,3}$. \\ ${ }^{1}$ Department of Neurosurgery, John Radcliffe Hospital, Oxford, UK \\ ${ }^{2}$ Nuffield Department of Surgical Sciences, University of Oxford, Oxford, UK \\ ${ }^{3}$ Nuffield Department of Clinical Neurosciences, University of Oxford, Oxford, UK \\ The research was supported by the National Institute for Health Research \\ (NIHR) Oxford Biomedical Research Centre (BRC).
}

\begin{abstract}
Background Trigeminal Neuropathic Pain (TNP) is a chronic facial pain syndrome caused by a lesion or disease affecting one or more branches of the trigeminal nerve. It may for example result from accidental injury to a branch of the trigeminal nerve by trauma or during surgery; it may also be idiopathic. TNP is typically constant, in contrast to most cases of the commoner trigeminal neuralgia. In some cases pain may be refractory to pharmacological treatment. Peripheral nerve field stimulation (PNFS) is recognized as an effective minimally invasive surgical treatment option for this debilitating condition. To date, stimulation has used conventional tonic waveforms which generate paraesthesia in the stimulated area. This is the first report of the use of paraesthesia free burst pattern stimulation for TNP.
\end{abstract}

Methods 7 patients were treated at the John Radcliffe Hospital for TNP from 2016 to 2018. Mean duration of pre operative symptoms was 5 years. All patients had exhausted pharmacological measures to limited effect. The initial 3 patients had tonic stimulation with the subsequent 4 having burst stimulation. Outcome was assessed using the Numeric Pain Rating Scale (NPRS) preoperatively and postoperatively at 3 and 6 months and one year. Side effects and complications were also assessed as well as reduction in analgesic medication use.

Results All patients achieved pain reduction of at least $50 \%$ at 6 months (range 50 $100 \%$, mean $81 \%, p=0.0082$ ). Those in the burst stimulation group were paraesthesia free. One patient developed a postoperative infection for which the system had to be removed, and is awaiting reimplantation. There were no other complications in either group.

Conclusion Burst stimulation conferred similar pain control to tonic stimulation in our small cohort, and there were similar reductions in pain medication use. An additional benefit of burst stimulation is freedom from paraesthesia. Larger scale studies are needed to further evaluate burst stimulation and compare its efficacy with that of tonic stimulation.

Keywords: Peripheral nerve stimulation, neuromodulation, trigeminal neuropathic pain, post herpatic neuralgia, burst stimulation. 


\section{Introduction}

Trigeminal neuropathic pain (TNP) is an uncommon facial pain syndrome that results from damage to the trigeminal nerve or one of its branches. It may be caused by trauma, or by surgery (including dental procedures, ENT procedures, or intracranial surgery in the posterior fossa). Unlike the episodic pain experienced by the majority of patients with the much commoner condition of trigeminal neuralgia (TN), TNP is continuous. It is typically described as dull, boring, or burning, and may be associated with an area of allodynia. It is commoner in females. TNP is differentiated from the neuropathic pain that can be an unfortunate consequence of intentional damage to the trigeminal system in the treatment of TN [1], the latter being accompanied by dense sensory loss in the painful area, and being referred to as trigeminal deafferentation pain (TDP) or anaesthesia dolorosa. Neuropathic facial pain may also result from shingles (postherpetic neuralgia) or be idiopathic.

The medical treatment of neuropathic facial pain includes simple analgesics, antiepileptics (typically gabapentin or pregabalin), antidepressants (tricyclics such as amitriptyline or serotonin-noradrenaline reuptake inhibitors such as duloxetine or venlafaxine), topical local anaesthetics, and opiates. Where all these measures are ineffective, or where medication causes intolerable side effects, neuromodulation may be an option. Stimulation has been applied at a range of sites, including peripherally using subcutaneous electrodes in the face [2-9], at the Gasserian ganglion [10-12], and centrally with high cervical spinal cord stimulation (targetting the spinal trigeminal nucleus) [13-15], deep brain stimulation [16] (targetting the ventroposteromedial nucleus of the thalamus and/or the periaqueductal grey matter), or motor cortex stimulation [17-19].

Of all these options, peripheral nerve field stimulation (PNFS) is the least invasive, and several case series have reported good results. All previously reported series of facial PNFS have used stimulation patterns that evoke paraesthesia. The necessity or not of paraesthesia for effective pain relief in neuromodulation has been a topic of great interest in the last decade. Traditionally, following from the gate control theory of Melzack and Wall [20], it was believed that paraesthesia was necessary for analgesia. Until recent years, the commonest form of neuromodulation, spinal cord stimulation (SCS), universally operated with a regular stream of pulses, usually at a frequency of $40-60 \mathrm{~Hz}$, a pattern called 'tonic' stimulation. This evokes paraesthesia, which many patients find irritating, in some cases to the extent that they cannot tolerate the treatment. The paraesthesia frequently extends beyond the painful area, and because of movement of the spinal cord within the thecal sac its intensity varies with posture, which may necessitate frequent adjustment of stimulator settings.

More recently, it has become clear that paraesthesia is actually not a prerequisite for analgesia in SCS. Effective pain relief has been demonstrated with SCS systems that deliver stimulating pulses in short bursts [21-26], or continuously but at much higher frequencies [27-30], both of which can operate without generating any paraesthesia at all. Many centres now use paraesthesia-free 
stimulation of one type or another routinely. Most SCS patients when given the option prefer not to have paraesthesia [25].

Relatively little is known about whether paraesthesia free pain relief is possible with PNFS, but if so, it seems likely that patients will prefer pain relief without paraesthesia at this site too. A study in occipital nerve stimulation (ONS) [31] suggested that indeed paraesthesia may not be essential for analgesia. In this study a group of patients who were responsive to tonic ONS for migraine had their stimulators turned down to just below the threshold of perception of the stimulation; despite the lack of paraesthesia they still experienced significant pain relief, although less so than when the system was on normal settings. It is not clear if the relief was less because of the lack of paraesthesia, or simply because of the need to turn the stimulus level down; therefore while this study proved that paraesthesia is not a prerequisite for pain relief in PNFS, it does leave open the possibility that it is necessary for optimal benefit. Recently, two cases of occipital neuralgia that were successfully treated using burst stimulation of the occipital nerves have been reported, showing that pain relief without paraesthesia is achievable using this waveform peripherally [32]. To date, the application of burst stimulation for refractory facial pain has not been assessed.

In the series presented here, the first three patients were treated with standard tonic PNFS. Implantable pulse generators capable of both tonic and burst pattern PNFS then became available, and the last 4 patients were treated with these. We believe this is the first reported use of paraesthesia-free peripheral stimulation for TNP.

\section{Methods}

\section{Patient selection}

All patients were referred to our unit by a neurologist or headache specialist. Each underwent outpatient reviews by a neurosurgeon and a neuropsychologist, following which they were discussed at a multidisciplinary team (MDT) meeting where suitability for neuromodulation was decided.

Before being considered for surgical intervention, patients had to have exhausted adequate trials of appropriate classes of medications, including antiepileptics and antidepressants. In cases where symptoms were compatible with trigeminal neuralgia, MRI was performed to exclude neurovascular conflict prior to consideration of neuromodulation.

\section{Trialling}

All patients underwent an initial percutaneous trial procedure. With the patient supine under general anaesthesia, leads were inserted subcutaneously from the temple region through Tuohy needles, and secured to the skin with a suture at their exit points. The leads were connected to an external stimulator for trialling over a seven day period. Initial confirmation of coverage of the painful area was 
performed with tonic stimulation in all cases, following which the latter 4 patients were also trialled in burst mode. At the end of the trial the leads were removed.

\section{Permanent implants}

Following successful trials (at least 50\% pain reduction with tolerable side effects), and after a gap of several weeks to minimise the chance of infection, permanent leads were implanted at the same locations as the trial leads and tunnelled subcutaneously, running over the ear and then turning downward to reach a subclavicular pocket where an implantable pulse generator was attached. The tonic stimulation patients were implanted with Medtronic model 3877 8contact Octad (45 or $60 \mathrm{~cm})$ leads driven either by model 37702 PrimeADVANCED (non-rechargable) or 97714 RestoreSensor SureScan MRI (Rechargable) implantable pulse generators (IPGs). The Burst stimulation group had Abbott model 3186 8-contact Octrode $(60 \mathrm{~cm})$ leads driven by Prodigy MRI BurstDR 3772 IPGs (burst \& tonic stimulation modes). In burst mode, pulse width was set at $1000 \mu$ s and Frequency to $40 \mathrm{~Hz}$, and stimulation amplitude was set at $60 \%$ of perception threshold. Patients were discharged home later the same day or the following day.

\section{Data collection}

All patients were prospectively followed up with pre and post operative Numeric Pain Rating Scale (NPRS) scores. Medications used pre and postoperatively were also recorded, and any side effects of stimulation were noted. Follow up time points were 3 months, 6 months and one year. 

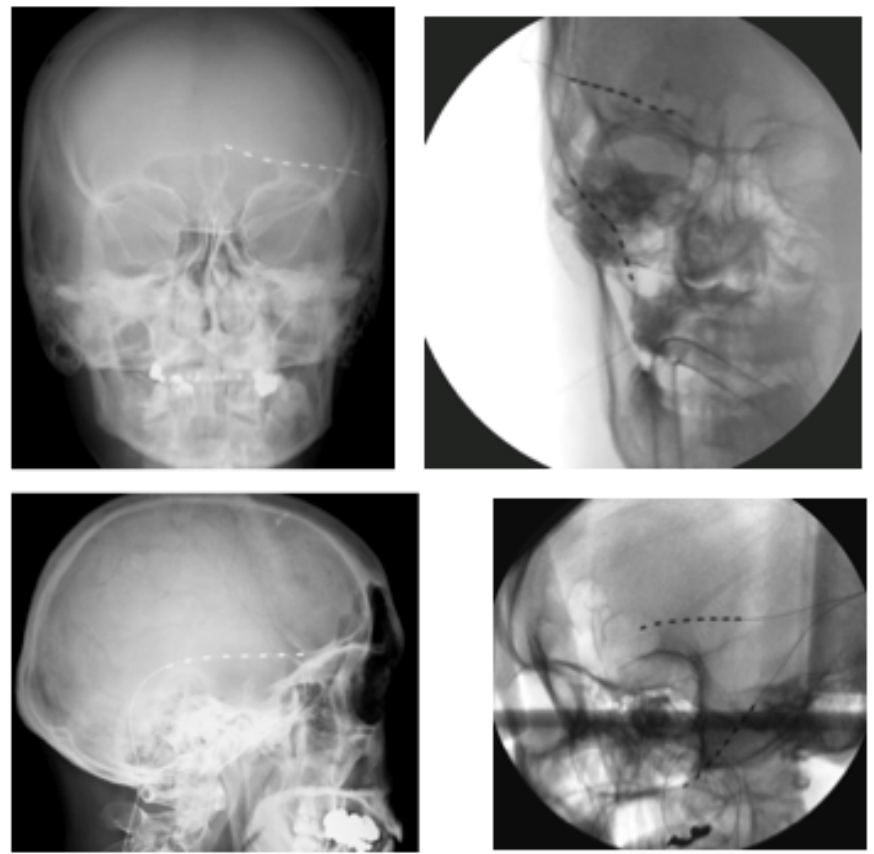

Fig 1. Intra \& post op x-rays demonstrating PNFS Probe positions.

\section{Results}

7 patients were trialled and all obtained at least $50 \%$ pain relief and were therefore permanently implanted. Patient demographics and the details of their TNP are summarised in table 1, and each case is described below. The first 3 patients received systems that only operated in tonic mode, while the last 4 patients received IPGs capable of both tonic and burst stimulation. After trialling, all of the latter group of 4 chose to remain on burst stimulation.

Table 1. Patient Demographics, Symptoms and Diagnosis

\begin{tabular}{|l|l|l|l|l|l|}
\hline ID: & Age/Sex: & Presenting Symptoms: & $\begin{array}{l}\text { Pain Duration } \\
\text { (years): }\end{array}$ & Pain Location: & Diagnosis: \\
\hline 1 & $61 \mathrm{M}$ & $\begin{array}{l}\text { Sudden onset of severe sharp } \\
\text { shooting facial pain }\end{array}$ & 14 & $\begin{array}{l}\text { Left face from the } \\
\text { left eye to the } \\
\text { tragus of the ear. }\end{array}$ & $\begin{array}{l}\text { Idiopathic } \\
\text { TNP }\end{array}$ \\
\hline 2 & $57 \mathrm{~F}$ & $\begin{array}{l}\text { Severe intractable stabbing face } \\
\text { pain }\end{array}$ & 6 & $\begin{array}{l}\text { Left periorbital \& } \\
\text { retro orbital }\end{array}$ & $\begin{array}{l}\text { Idiopathic } \\
\text { TNP }\end{array}$ \\
\hline 3 & $66 \mathrm{~F}$ & $\begin{array}{l}\text { Severe constant face \& head } \\
\text { pain with pressure \& } \\
\text { paraesthesia component }\end{array}$ & 5 & $\begin{array}{l}\text { Most marked R } \\
\text { cheek below eye }\end{array}$ & $\begin{array}{l}\text { Idiopathic } \\
\text { TNP }\end{array}$ \\
\hline 4 & $41 \mathrm{~F}$ & $\begin{array}{l}\text { Sudden onset headache \& } \\
\text { constant pulsing scalp \& face } \\
\text { pain }\end{array}$ & 7 & Left scalp \& face & $\begin{array}{l}\text { Idiopathic } \\
\text { TNP }\end{array}$ \\
\hline 5 & $38 \mathrm{~F}$ & $\begin{array}{l}\text { Severe sharp \& pounding facial } \\
\text { pain }\end{array}$ & 4 & $\begin{array}{l}\text { Right side of head } \\
\text { \& behind R eye }\end{array}$ & $\begin{array}{l}\text { TNP - ? } \\
\text { related to } \\
\text { neurosarcoid }\end{array}$ \\
\hline 6 & $32 \mathrm{~F}$ & $\begin{array}{l}\text { Constant facial pain with severe } \\
\text { shooting, stabbing } \\
\text { exacerbations }\end{array}$ & 5 & $\begin{array}{l}\text { Left temporal and } \\
\text { V1/V2 regions } \\
\text { from ear to nose }\end{array}$ & $\begin{array}{l}\text { Post herpetic } \\
\text { TNP }\end{array}$ \\
\hline 7 & $52 \mathrm{~F}$ & $\begin{array}{l}\text { Chronic sharp stabbing facial } \\
\text { pain }\end{array}$ & 5 & $\begin{array}{l}\text { Left periorbital \& } \\
\text { V1/2 region }\end{array}$ & $\begin{array}{l}\text { Post surgical } \\
\text { TNP }\end{array}$ \\
\hline
\end{tabular}


Patient 1 is a 61 year old male with intractable left facial pain of unknown aetiology. The pain had been present for over 14 years before PNFS was performed, but he could still clearly recall the day it began. On that day he awoke with a sharp shooting pain in the left side of his face, and remarked that it was so intense that it will be etched onto his memory forever. He confessed to close friends and his GP that over the 14 years he had contemplated suicide. The pain was at 10/10 for much of the day and he often could not eat due to the pain and associated nausea. He was woken most nights at 3am with severe pain and could not get back to sleep. He could not enjoy holidays or spending time with his granddaughters. He struggled to hold down his job as a lorry driver due to being too exhausted to work from the constant pain.

He had tried medications including tramadol, co-dydramol, nortriptyline, fluoxetine, gabapetin, amitriptyline, and antiepileptics. No benefit was afforded from capsaicin cream, cranial physiotherapy or botulinum toxin. Cryotherapy, which did work, only afforded him a few weeks of pain relief. Acupuncture made his symptoms worse and radiofrequency ablation also had no benefit. After repeated funding attempts and letters of support from his GP, maxiollofacial surgeon, pain consultant and neuropsychologist, he was finally able to obtain PNFS treatment. A left temporal/V2 region electrode was inserted and trialled in tonic mode. Excellent results were achieved with complete coverage over the left side of his face in the distribution of his pain. He proceeded for implantation of the permanent electrodes and insertion of the IPG. His average baseline NPRS score was $9 / 10$ with postoperative scores of $2 / 10$ at 3 months, $1 / 10$ at 6 months, and $1 / 10$ at 1 year follow up. He managed to come off all medications and continues to work. In follow up clinics, he has tolerable pins and needles in the distribution of stimulation, but other than that has no complaints and his average level of pain remains at $1 / 10$.

Patient 2 is a 57 year old female with a 6 year history of severe intractable stabbing pain around and above the left eye that averaged 9/10 in severity but was often 10/10. There did not seem to be any precipitating cause and over the years she had seen a number of specialists and numerous analgesics were tried including carbamazepine, topirimate, gabapentin, amitriptyline, tramadol, naproxen, sumitriptan, etoricoxib, citalopram, baclofen and pizotifen. She also suffered from migraine in addition to the facial pain. She felt that life was unbearable. Her first surgical intervention was a glycerol gangliolysis since in the early stages, she was thought to have atypical trigeminal neuralgia. Unfortunately, this did not afford her any pain relief. At this point, she responded well to greater occipital nerve blocks although with only a few weeks of pain relief on each occasion. Following this occipital nerve stimulation was trialled, unfortunately without success. She was then referred for PNFS.

She was trialled with tonic stimulation for a week after insertion of a left supraorbital PNFS electrode. Preoperative NPRS was 9/10, and postoperatively NPRS was $0 / 10$ most of the time, with occasional breakthrough pain requiring 
analgesia. She sometimes had the sensation of a tight band over the forehead, which she managed by periodically reducing stimulation and she tolerated the paraesthesia in the same way.

Patient 3 is a 66 year old female with pain for 5 years affecting the right side of her head and face, predominately below the eye but also a pressure-like component over the forehead. There were no autonomic features to her symptoms. There was often an associated painful paraesthesia component to the pain on the cheek. She described it as severe and continuous pain with frequent exacerbations. Her sleep was often affected as she was never free from the pain which she felt 'controlled her life'. She had been seen regularly by a pain specialist and tried numerous medications including co-codamol, amitriptyline, nortriptyline, duloxetine, pregabalin \& lofepramine. At the point of referral to the functional neurosurgery unit, she was on paracetamol and gabapentin 300mg TDS with modest results. She had also tried physiotherapy and acupuncture which only worked to a moderate degree for 2 days.

Right sided supra and infraorbital nerve blocks were performed, which achieved $100 \%$ pain reduction but this was of course short lived with the pain recurring within 2 days. She proceeded for insertion of PNFS electrodes to the supra \& infraorbital regions with excellent results. Her baseline NPRS was 8/10, with a postoperative score of $2 / 10$, a $75 \%$ pain reduction, and complete coverage of the region of pain. She managed to reduce her dose of paracetamol and stopped gabapentin completely. The associated paraesthesia is tolerated.

\section{Burst facial PNFS}

Patient 4 is a 41 year old female with a 7 year history of left face pain. This had started suddenly and intially had a pulsating quality, but subsequently became constant. The pain radiated up from the left side of the neck, around the ear and to the face above and below the left eye which is where it was most severe. Stress and occasionally minor head movement could exacerbate it. She was reviewed in multiple pain clinics but had limited benefit from morphine, zomorph, ibuprofen, paracetamol, gabapendin, amitriptyline, and fluoxetine. Four years prior to PNFS she had undergone an occipital rhizolysis which improved the more posterior component of her scalp pain temporarily, but a repeat of this procedure two years later was ineffective.

Her pain caused her to be absent from work on a number of occasions, which resulted in disciplinary proceedings. She was also taking antidepressants and had tried various mindfulness techniques as part of her psychological therapy. After referral to the neuromodulation service she underwent a trial insertion of left sided supra and infraorbital PNFS electrodes with good results, and so received a permanent implant. In burst stimulation mode her postoperative NPRS was $2 / 10$, compared to a baseline of $7 / 10$, a $70 \%$ reduction in pain, and there was $100 \%$ coverage of the painful area. She now uses far less analgesia, only gabapentin at a reduced dose, and still takes fluoxetine. She has no features of paraesthesia. 
Patient 5 is a 38 year old female who presented with a 4 year history of pain affecting the right side of her head, in the V1 and V2 distribution of the trigeminal nerve, worst behind her right eye. She described a sharp and pounding pain, and although the severity fluctuated over time, the pain was present continuously. Pain intensity was 7-8/10 on average, up to 10/10 on bad days. Analgesic medication provided modest relief and she had tried codcodamol, ibuprofen, pregabalin, duloxetine and lidocaine patches. Further coping strategies included mindfulness, resting and distraction. The constant pain affected her ability to work and to play an active role with her family. She lost her job following an 18 month period of sick leave.

She had a complex background of neurosarcoid with steroid-induced type 2 diabetes, bilateral optic neuropathy and blindness in the right eye. There was also right sided sensorineural hearing loss which is still being investigated, She had stable lung sarcoidosis but moderate to severe cardiomyopathy. In addition to her pain medications, she was taking prednisolone, azathioprine, leflunomide as well as alendronic acid and co-trimoxazole. The additional risks of implanting a device in the presence of her other comorbidites and immunosuppression was discussed in detail with her. She underwent insertion of right sided supra and infraorbital PNFS electrodes with a successful trial. After insertion of the permanent system in burst mode coverage of the region of pain was over $90 \%$ with her preoperative NPRS of 8/10 falling to 4/10 with no paraesthesia and a reduction in analgesic use.

Patient 6 is a 32 year old female with a 5 year history of left sided V1 and V2 division trigeminal nerve pain, attributed to shingles of the ophthalmic division of the left trigeminal nerve (including eye ulceration) prior to the onset of pain. The pain was worst in the forehead and temporal region but extended to the nose and ear. It was described as constant pain with intermittent severe stabbing and shooting exacerbations that could occur at any time, day or night. Stress, lack of sleep, bright lights, strong smells and any form of exercise could worsen the symptoms. High resolution MRI scans did not identify any lesions. She had some benefit initially from diclofenac but she developed gastric side effects. Other medications were of limited benefit. She tolerated tramadol, although this caused a degree of sedation. Lignocaine patches and capsaicin cream had no effect. She could not tolerate other antineuropathic medications or carbamazepine. Her social life and ability to progress at work were severely limited due to the constant pain. She underwent trial left sided supra and infraorbital PNFS electrode placement with excellent results so proceeded for permanent implantation. Pre-operative NPRS was $6 / 10$ which reduced postoperatively to $1 / 10$ in burst mode, with $100 \%$ coverage of the region of pain. Medication was reduced to prn ibuprofen or paracetamol and she does not have any paraesthesia.

Patient 7 is 52 year old female with a 5 year history of left sided chronic periorbital V1 and V2 division trigeminal neuropathic pain. She described a sharp stabbing pain which could be precipitated by touch, wind, rain, moving her face, applying make-up, lack of sleep and eating. The trigeminal neuropathic pain was thought to be originally secondary to surgery for a frontal sinus abscess via an ethmoidal incision near the left orbit. Initial treatment by a supraorbital 
neurectomy achieved good control for several years but the pain gradually returned in the same distribution. Acupuncture, TENS machines, amitriptyline and gabapentin were all of limited benefit. She was struggling with work and social involvement.

A single left supraorbital PNFS electrode was inserted to good effect initially and worked well for a number of years but unfortunately became dislodged requiring lead revision four years after its initial insertion. This revision afforded her a few more years of good pain control but eventually this PNFS stopped working for unknown reasons. A new system with left sided supra and infraorbital electrodes delivering burst stimulation was inserted, again with good results. Pre operative NPRS was $10 / 10$ with a post operative score of 1/10 with $100 \%$ coverage and no paraesthesia. Preoperatively she was taking cocodamol, naproxen and pregabalin. All analgesic medication was stopped post operatively. Unfortunately this system became infected necessitating removal several months after implantation. She is presently awaiting re-implantation.

\section{Overall results}

Table 2 summarises the stimulation mode, electrode locations, preoperative and follow up NPRS scores, and medication changes for each patient. Overall the treatment was highly successful, with a mean preoperative NPRS across all seven patients of 8.14 , falling to a mean of 1.57 at 6 months, a reduction of $81 \%$ $(p=0.0082$, two-tailed sign test).

The tonic stimulation patients' mean preoperative NPRS was 8.66 , falling to 1.0 at 6 months (88\% improvement), while the burst stimulation patients improved from 7.75 to 2.0 (74\% improvement). Both tonic and burst stimulation therefore appear very effective but patient numbers in the two groups are too small to permit statistical comparison of efficacy between stimulation modes. The most notable difference between the groups was that while all of the tonic stimulation patients experienced paraesthesia, this was present in none of the burst stimulation cases. 
Table 2. Pre vs Post implantation NPRS, pain reduction and side effects.

Supraorbital (SO); Infraorbital (IO)

\begin{tabular}{|c|c|c|c|c|c|c|c|c|c|c|}
\hline I.D & $\begin{array}{l}\text { Stimulation } \\
\text { Type }\end{array}$ & $\begin{array}{l}\text { Lead } \\
\text { Location }\end{array}$ & $\begin{array}{l}\text { NPRS } \\
\text { Preop }\end{array}$ & $\begin{array}{l}\text { NPRS } 3 \\
\text { months } \\
\text { postop }\end{array}$ & $\begin{array}{l}\text { NPRS } 6 \\
\text { months } \\
\text { postop }\end{array}$ & $\begin{array}{l}\text { NPRS } 1 \\
\text { year } \\
\text { postop }\end{array}$ & $\begin{array}{l}\% \text { NPRS } \\
\text { reduction } \\
\text { at } 6 \\
\text { months }\end{array}$ & Meds Pre PNFS & Meds Post PNFS & Side Effects \\
\hline 1 & Tonic & $\begin{array}{l}\text { Left } \\
\text { temporal }\end{array}$ & 9 & 2 & 1 & 1 & 89 & $\begin{array}{l}\text { Tramadol } 100 \mathrm{mg} \text { qds } \\
\text { Co-dydramol } 30 / 500 \times 2 \text { qds } \\
\text { Nortriptyline } 75 \mathrm{mg} \text { od } \\
\text { Fluoxetine } 40 \mathrm{mg} \text { od } \\
\text { Gabapentin } 1200 \mathrm{mg} \text { tds }\end{array}$ & Off & Paraesthesia \\
\hline 2 & Tonic & Left SO & 9 & 0 & 0 & 0 & 100 & $\begin{array}{l}\text { Gabapentin } 1200 \mathrm{mg} \text { tds } \\
\text { Topiramate } 25 \mathrm{mg} \mathrm{tds} \\
\text { Amitriptyline } 20 \mathrm{mg} \text { od } \\
\text { Baclofen } 10 \mathrm{mg} \text { od } \\
\text { Tramadol } 100 \mathrm{gm} \text { qds } \\
\text { Naproxen } 250 \mathrm{mg} \text { tds } \\
\text { Simitriptan } 50 \mathrm{mg} \text { prn }\end{array}$ & $\begin{array}{l}\text { Topiramate } 25 \mathrm{mg} \text { tds } \\
\text { Amitriptyline } 10 \mathrm{mg} \text { prn } \\
\text { Baclofen } 10 \mathrm{mg} \mathrm{prn} \\
\text { Sumatriptan } 50 \mathrm{mg} \text { prn }\end{array}$ & $\begin{array}{l}\text { Paraesthesia \& } \\
\text { tight band } \\
\text { across } \\
\text { forehead on } \\
\text { higher stim } \\
\text { levels }\end{array}$ \\
\hline 3 & Tonic & $\begin{array}{l}\text { Right SO } \\
\& 10\end{array}$ & 8 & 2 & 2 & 2 & 75 & $\begin{array}{l}\text { Gabapentin } 600 \mathrm{mg} \text { tds } \\
\text { Piroxicam gel } \\
\text { Tramadol } 100 \mathrm{mg} \mathrm{qds} \\
\text { Paracetamol } 1 \mathrm{~g} \mathrm{qds}\end{array}$ & Paracetamol prn & Paraesthesia \\
\hline 4 & Burst & $\begin{array}{l}\text { Left SO \& } \\
10\end{array}$ & 7 & 2 & 2 & 2 & 71 & $\begin{array}{l}\text { Zomorph } 10 \mathrm{mg} \text { bd } \\
\text { Gabapentin } 1200 \mathrm{mg} \text { tds } \\
\text { Fluoxetine } 40 \mathrm{mg} \text { od } \\
\text { lbuprofen } 400 \mathrm{mg} \text { tds } \\
\text { Paracetamol } 1 \mathrm{~g} \mathrm{qds} \\
\end{array}$ & $\begin{array}{l}\text { Gabapentin } 600-1200 \mathrm{mg} \\
\text { od prn- max 3x per wk }\end{array}$ & nil \\
\hline 5 & Burst & $\begin{array}{l}\text { Right SO } \\
\& 10\end{array}$ & 8 & 4 & 4 & 4 & 50 & $\begin{array}{l}\text { Pregabalin } 300 \mathrm{mg} \text { bd } \\
\text { ibuprofen } 400 \mathrm{mg} \text { tds } \\
\text { co-codamol } 30 / 500 \times 2 \text { qds } \\
\text { lidocaine patch } 5 \% \text { od } \\
\text { duloxetine } 60 \mathrm{mg} \text { bd }\end{array}$ & $\begin{array}{l}\text { Preganalin } 150 \mathrm{mg} \text { od } \\
\text { Ibuprofen } 400 \mathrm{mg} \text { tds prn } \\
\text { Co-codamol } 30 / 500 \times 2 \mathrm{prn} \\
\text { Lidocaine patch } 5 \% \mathrm{prn} \\
\text { Duloxetine } 60 \mathrm{mg} \text { bd }\end{array}$ & nil \\
\hline 6 & Burst & $\begin{array}{l}\text { Left SO \& } \\
10\end{array}$ & 6 & 1 & 1 & - & 83 & $\begin{array}{l}\text { Paracetamol } 1 \mathrm{~g} \mathrm{qds} \\
\text { Tramadol } 150 \mathrm{mg} \mathrm{qds}\end{array}$ & $\begin{array}{l}\text { Paracetamol prn } \\
\text { lbuprofen prn }\end{array}$ & nil \\
\hline 7 & Burst & $\begin{array}{l}\text { Left SO \& } \\
10\end{array}$ & 10 & 1 & 1 & - & 90 & $\begin{array}{l}\text { Pregabalin } 150 \mathrm{mg} \text { bd } \\
\text { Co-codamol } 30 / 500 \times 2 \text { qds } \\
\text { Naproxen } 500 \mathrm{mg} \text { bd }\end{array}$ & Off & $\begin{array}{l}\text { System } \\
\text { removal due to } \\
\text { infection }\end{array}$ \\
\hline
\end{tabular}




\section{Discussion}

Tonic PNFS for TNP has been used for over a decade, with positive results in post-traumatic, post-surgical, post-herpetic, and idiopathic TNP. In this cohort, we have replicated the positive results seen in other published studies with the added benefit of sparing the patient the side effect of paraesthesia in the region of stimulation. Pain relief was excellent with both tonic and burst stimulation. One patient saw a $50 \%$ reduction in their NPRS, with all others achieving at least $70 \%$ improvement. All patients with tonic stimulation experienced paraesthesia, which was present in no patient with burst stimulation. This group as a whole achieved a large (mean $81 \%$ reduction in NPRS) and statistically significant $(p=0.0082)$ benefit. The numbers in this series are too small to permit statistical comparison of the relative efficacy of the two stimulation patterns. Larger studies are needed to further investigate whether either of the waveforms is superior, but at the very least this series clearly shows that paraesthesia is not necessary for excellent pain relief with PNFS, at least in the face.

All patients were able to either reduce or completely stop their pain medications post PNFS implantation. Two patients stopped all analgesics, and two reduced to just paracetamol or paracetamol plus ibuprofen, in both cases taken on a PRN basis. Of the remaining three, one ceased taking 3 medications, and another stopped 4 medications. Only one patient (the patient whose NPRS reduced by only $50 \%$ ) remained on the same set of medications as before stimulation; of the five drugs she was taking, the dose of one was reduced and three others were changed from a regular to PRN prescription. Five of seven patients were taking strong opiates preoperatively; after implantation no patient remained on these.

Other than paraesthesia, no side effects were reported but there was one complication of a delayed infection in a patient in the burst stimulation group. This required system removal. Prior to removal the patient had a NPRS of 1 , the preoperative NPRS having been 10 . She is currently awaiting reimplantation.

A number of other studies have demonstrated good results from facial PNFS for neuropathic pain. Johnson and Burchiel [2] trialled a group of 11 patients with facial pain after facial trauma or zoster, and implanted 10 of them. 7 of 10 obtained $>50 \%$ pain relief, with a mean pain score reduction of $58 \%$, and 7 of 10 patients also reduced their analgesic use. 30\% required re-operation. Slavin et al [3] trialled 30 and implanted 22 patients with stimulators targetting trigeminal, occipital or both targets. Causative factors for pain included surgery and trauma, but 10 of the 30 patients were idiopathic. 5 had their electrodes removed, of which one explant was because of infection, two because of complete pain resolution with stimulation switched off, and two because of diminishing effect. Of the remaining 17 patients, 14 had $>50 \%$ pain reduction after a mean follow up of 35 months. Three required reoperation. Stidd et al [4] described 3 cases, one postherpetic, one post trauma, and one post surgery, with a mean pain reduction of $87 \%$. Two patients had complete relief of pain and stopped all analgesic medication. The third patient had a pain reduction from $10 / 10$ to $4 / 10$, but required re-siting of the lead due to migration. Feletti [5] reported a series of 6 cases with an average VAS reduction of 73\%. 2 of 6 patients reported reduced 
analgesic use. Amin et al [6] trialled supraorbital stimulation in 16 patients with supraorbital neuralgia who had responded to disgnostic supraorbital nerve blocks. 10 were successful and proceeded to full implantation. In the fully implanted patients the mean headache intensity was reduced from 7.5/10 to 3.5/10 and opioid consumption was halved. Ellis et al [8] trialled 35 and fully implanted 15 patients. Outcome was measured simply in terms of whether or not patients were satisfied with the results; on this basis $90 \%$ of implanted cases were successful at one year, although by 3 years this had fallen to $51 \%$. Weiner et al [7] reported on 10 patients implanted with a novel wirelessly powered percutaneous device, who obtained a mean $82 \%$ pain relief.

The series of Johnson and Burchiel, and Stidd, included patients who all had an identified underlying cause for their TNP. In both of Slavin's and Feletti's series, one third (10 of 30 and 2 of 6 patients respectively) were idiopathic. This was true of an even larger proportion of our patients ( 4 out of 7 cases). Perhaps surprisingly, these patients had a higher mean pain score reduction (84\%) than those with a clear aetiology (74\%). The numbers are too small for meaningful statistical comparison, and the mean pain reduction in the with-diagnosis group is heavily influenced by the single patient whose pain relief $(50 \%)$ was a lot lower than all the others. However, this clearly demonstrates that, provided the pain clearly fits the pattern of TNP and care is taken with patient selection, the lack of an identified causative event is no barrier to a good response.

It is difficult to be entirely certain whether this treatment is true peripheral nerve stimulation (PNS, i.e. activating fibres within a named nerve) or peripheral nerve field stimulation (PNFS, i.e. activating fibres diffusely within the skin), particularly where the treatment is paraesthesia free. Both terms have been used among the previous studies described above. We placed our electrodes with the intention of directly covering the area of pain, and did not evoke paraesthesia throughout a named nerve distribution, and on this basis have taken the view that this is predominantly PNFS. However the electrodes were all in a position crossing a named nerve (supraorbital, infraorbital, or auriculotemporal) and it is possible that nerve stimulation was occurring in some cases.

The results of PNFS in this series were swift. All patients achieved effective analgesia within our seven day trial period. This is in keeping with other studies of facial PNFS and with the general experience of PNFS elsewhere in the body, and is in contrast to occipital nerve stimulation in headache syndromes, where the benefits appear to accrue over periods as long as several months [33]. In basing the decision about whether to permanently implant on a seven day trial, we are making the assumption that patients who would benefit from this treatment will always respond quickly. It is important to note that by doing this it is possible that we might inadvertently exclude 'slow responders' from treatment.

The occurrence of paraesthesia with tonic neuromodulation, both peripherally and in the spine, has made fully blinded trials impossible in the past. Paraesthesia-free stimulation changes that, and blinded trials are starting to 
appear [29]. Although the results of facial PFNS in TNP, from this study and those that have gone before, seem convincing, it would still be ideal to subject them to a proper trial to provide class 1 evidence of effect. The rapidity of the onset of effect means that the randomised part of any trial would not need to be lengthy.

\section{References}

1. Burchiel, K.J., A new classification for facial pain. Neurosurgery, 2003. 53(5): p. 1164-6; discussion 1166-7.

2. Johnson, M.D. and K.J. Burchiel, Peripheral stimulation for treatment of trigeminal postherpetic neuralgia and trigeminal posttraumatic neuropathic pain: a pilot study. Neurosurgery, 2004. 55(1): p. 135-41; discussion 141-2.

3. Slavin, K.V., et al., Trigeminal and occipital peripheral nerve stimulation for craniofacial pain: a single-institution experience and review of the literature. Neurosurg Focus, 2006. 21(6): p. E5.

4. Stidd, D.A., et al., Peripheral nerve stimulation for trigeminal neuropathic pain. Pain Physician, 2012. 15(1): p. 27-33.

5. Feletti, A., et al., Peripheral trigeminal nerve field stimulation: report of 6 cases. Neurosurg Focus, 2013. 35(3): p. E10.

6. Amin, S., et al., Peripheral nerve stimulator for the treatment of supraorbital neuralgia: a retrospective case series. Cephalalgia, 2008. 28(4): p. 355-9.

7. Weiner, R.L., C.M. Garcia, and N. Vanquathem, A novel miniature, wireless neurostimulator in the management of chronic craniofacial pain: Preliminary results from a prospective pilot study. Scand J Pain, 2017. 17: p. 350-354.

8. Ellis, J.A., J.C. Mejia Munne, and C.J. Winfree, Trigeminal branch stimulation for the treatment of intractable craniofacial pain. J Neurosurg, 2015. 123(1): p. 283-8.

9. Jakobs, M., et al., Subcutaneous trigeminal nerve field stimulation for refractory trigeminal pain: a cohort analysis. Acta Neurochir (Wien), 2016. 158(9): p. 1767-74.

10. Kustermans, L., et al., Stimulation of the Gasserian ganglion in the treatment of refractory trigeminal neuropathy. J Craniomaxillofac Surg, 2017. 45(1): p. 39-46.

11. Mehrkens, J.H. and U. Steude, Chronic electrostimulation of the trigeminal ganglion in trigeminal neuropathy: current state and future prospects. Acta Neurochir Suppl, 2007. 97(Pt 2): p. 91-7.

12. William, A., et al., Trigeminal and sphenopalatine ganglion stimulation for intractable craniofacial pain--case series and literature review. Acta Neurochir (Wien), 2016. 158(3): p. 513-20.

13. Tomycz, N.D., C.P. Deibert, and J.J. Moossy, Cervicomedullary junction spinal cord stimulation for head and facial pain. Headache, 2011. 51(3): p. 418-425. 
14. Chivukula, S., et al., Cervical and cervicomedullary spinal cord stimulation for chronic pain: efficacy and outcomes. Clin Neurol Neurosurg, 2014. 127: p. 33-41.

15. Velasquez, C., et al., Upper Cervical Spinal Cord Stimulation as an Alternative Treatment in Trigeminal Neuropathy. World Neurosurg, 2018.

16. Green, A.L., et al., Deep brain stimulation for neuropathic cephalalgia. Cephalalgia, 2006. 26(5): p. 561-7.

17. Raslan, A.M., et al., Motor cortex stimulation for trigeminal neuropathic or deafferentation pain: an institutional case series experience. Stereotact Funct Neurosurg, 2011. 89(2): p. 83-8.

18. Rasche, D. and V.M. Tronnier, Clinical Significance of Invasive Motor Cortex Stimulation for Trigeminal Facial Neuropathic Pain Syndromes. Neurosurgery, 2016. 79(5): p. 655-666.

19. Brown, J.A. and J.G. Pilitsis, Motor cortex stimulation for central and neuropathic facial pain: a prospective study of 10 patients and observations of enhanced sensory and motor function during stimulation. Neurosurgery, 2005. 56(2): p. 290-7; discussion 290-7.

20. Melzack, R. and P.D. Wall, Pain mechanisms: a new theory. Science, 1965. 150(3699): p. 971-9.

21. Schu, S., et al., A prospective, randomised, double-blind, placebo-controlled study to examine the effectiveness of burst spinal cord stimulation patterns for the treatment of failed back surgery syndrome. Neuromodulation, 2014. 17(5): p. 443-50.

22. De Ridder, D., et al., A 2-center comparative study on tonic versus burst spinal cord stimulation: amount of responders and amount of pain suppression. Clin J Pain, 2015. 31(5): p. 433-7.

23. De Ridder, D., et al., Burst spinal cord stimulation: toward paresthesia-free pain suppression. Neurosurgery, 2010. 66(5): p. 986-90.

24. de Vos, C.C., et al., Burst spinal cord stimulation evaluated in patients with failed back surgery syndrome and painful diabetic neuropathy. Neuromodulation, 2014. 17(2): p. 152-9.

25. Deer, T., et al., Success Using Neuromodulation With BURST (SUNBURST) Study: Results From a Prospective, Randomized Controlled Trial Using a Novel Burst Waveform. Neuromodulation, 2018. 21(1): p. 56-66.

26. Courtney, P., et al., Improved Pain Relief With Burst Spinal Cord Stimulation for Two Weeks in Patients Using Tonic Stimulation: Results From a Small Clinical Study. Neuromodulation, 2015. 18(5): p. 361-6.

27. Kapural, L., et al., Novel 10-kHz High-frequency Therapy (HF10 Therapy) Is Superior to Traditional Low-frequency Spinal Cord Stimulation for the Treatment of Chronic Back and Leg Pain: The SENZA-RCT Randomized Controlled Trial. Anesthesiology, 2015. 123(4): p. 851-60.

28. De Andres, J., et al., Prospective, Randomized Blind Effect-on-Outcome Study of Conventional vs High-Frequency Spinal Cord Stimulation in Patients with Pain and Disability Due to Failed Back Surgery Syndrome. Pain Med, 2017. 18(12): p. 2401-2421.

29. Thomson, S.J., et al., Effects of Rate on Analgesia in Kilohertz Frequency Spinal Cord Stimulation: Results of the PROCO Randomized Controlled Trial. Neuromodulation, 2018. 21(1): p. 67-76. 
30. Sweet, J., et al., Paresthesia-Free High-Density Spinal Cord Stimulation for Postlaminectomy Syndrome in a Prescreened Population: A Prospective Case Series. Neuromodulation, 2016. 19(3): p. 260-7.

31. Slotty, P.J., et al., Occipital nerve stimulation for chronic migraine: a randomized trial on subthreshold stimulation. Cephalalgia, 2015. 35(1): p. 73-8.

32. Petersen, E., Improved ONS efficacy and increased pain relief in occipital neuralgia with burst stimulation: two cases. Stereotactic and Functional Neurosurgery, 2017. 95(Suppl 1): p. 375.

33. Magis, D., et al., Occipital nerve stimulation for drug-resistant chronic cluster headache: a prospective pilot study. Lancet Neurol, 2007. 6(4): p. 314-21. 